\title{
The Assessment of the Factors that Affect in the Academical Level of Students' Stress
}

\author{
Petrit Taraj \\ PhD Candidate, Universitety of Vlora Ismail Qemali, Vlorë \\ ptaraj2@gmail.com
}

\section{Doi:10.5901/jesr.2014.v4n6p139}

\begin{abstract}
This document investigates and seeks to evaluate the Factors' impact; self-management, the results of the study and the academical programs on the level of academical stress of the students from the University "Ismail Qemali" Vlora. The main aim of the study is to find relationships between the academic stressof the students and the factors affectingit, such as:selfmanagement, results of the study and academic programs. Carrying out this study, were used sample techniques with simple random selection of data collection conducted by the surveying technique. The researchers adapted a questionnaire about the academic stress of these students, which contained 69 questions. Statistical Package of Social Sciences (SPSS for Windows $X P)$ was used to conduct a surveillanceof the statistical data and analysis of factors affecting the growth of student's stress. The results of the study showed that $75.8 \%$ of the students have experienced a moderate stress and alot of stress. Also the data's analysis showed that is a correlation between the factors mentioned above and the academical stress experienced by students. Reducing the impact of these factors on increasing the academic stress on students may be an effective strategy for reducing the academic stress to university students. The results of this pilot study will serve researchers for a broader nationwide research, so that this reearch can have a resumptive value. Another objective of this study is the reliability and validity of the Likert's scale used by researchers, whethe rit is in accordance with the coefficients (Cronbach 's Alpha ( $\alpha \geq 0.7$ ) accepted as the norm in the social sciences. In our study the general coefficient of the rate Cronbach's Alpha= 0.9 (Excellent)
\end{abstract}

Keywords: stress, stress factor, academic stres, academic performance, level of stress.

\section{Introduction}

\subsection{Background of the study.}

The future of any nation belongs to the youth because they are the leaders of tomorrow, therefore, it is important to identify the reasons, symptoms, causes and effects of academic stress among students. Integrating in the understanding, society raises more than ever the acquisition of basic skills. A citizen of tomorrow's society must be equipped with some basic skills to integrate into a society that is becoming more flexible and more open to development of society and information.

Along with improvements in scientific era and the rapid development of information competitiveness among people has become increasingly intensive. As a result, people have become more vocal, and therefore, stress is a natural consequence. Although, proper stress is a $\mathrm{g}$ moment of self-education, it is also a motivation for people to actively advance. It does not affect only our thoughts and our feelings, but also ourbehavior patterns. However, overstressing causes problems and can have serious effects on people. Specifically, students who are adapted to a common surrounding, when coming to university, in a world completely new, experience stress and anxiety.

In light of this pilot study, conducted with students of the University of Vlora Ismail Qemali, it is expected to provide a reliable and available assessment of the level of academic stress as a result of the reponses of the surveyed students at the Faculty of Humanities. Currently, many studies are being made on the causes of stress and coping behaviors of the new generation (Stren, M. and Zevon, M.1990; Groer, M.W., Thomas, S.P. and Shoffer, D.1992; Mates, D. and Allison, K.R.1992; Plunkett, S.W., Radmacher, K.A. and Moll - Phanara, D. 2000). Studies have shown that schools are one of the main causes of stress for the younger generation and that stress is a significant catalyst and a precursor to depression (Plunkett, S.W., Radmacher, K.A. and Moll - Phanara, D.2000; Basch, C.E. and Kersch, T.B.,1986).

Academic stress experienced by university students has been the subject of numerous studies and examinations, and continues to be one of the most popular topics of researches.

Although, there is a positive side of stress to people, it also has negative influence. Consequently, to maintain a healthy body and mind, as well as in the development of normal operational functions, people need to understand stress 
in the correct way. Schuler believes that stresss is obvious in important opportunities; limitations and needs faced by individuals even when the results of these situations are not clear, then individuals build a kind of uncertainty in themselves (Schuler, R.S., 1980). This research used a relevant literature as the basis for identifying the causes of stress from different angles, to help academic staff in understanding the problems associated with stress faced by students in the university environment, continuing to provide assistance and preventive measures. Consequently, the value of this research is of great importance and the problems it addresses

\subsection{Statement of the Problem}

University students have many obstacles to overcome in order to achieve an optimal academic performance. A lot of researches have been looking to find a correlation between the factors that cause academic stress to university students and the effects that experienced stress causes in their academic performance (GPA). The problem of this study is not to determine the impact of academic stress experienced by students in academic achievement. The problem of our study is whether the factors identified by factor analysis are the cause of level increase of student's academic stress.

\subsection{Objectives of the Study}

This study seeks to prove the reliability and validity of the new instrument developed by researchers, following factorial analysis performed through the program Statistical Package of Social Sciences (SPSS for Windows XP). Study aims to find the impact that the factors havet: self-management, research results and academic programs, increasing or not the stress level of the students. Our ultimate goal is to find if there is a correlation between stress experienced by students during the spring semester 2013 and the factors mentioned above.

The hypothesis of the study:

$\mathrm{H}_{0}$ : Factors that are selected by researchers have no impact on level increase of academic stress.

$\mathrm{H}_{1}:$ The stress factors identified in this study affect the level increase of student's academic stress.

\section{Literature Review}

Academic stress is the result of the combination of related academic requirements that exceed the adaptive resources available to an individual. Compared with their domestic counterparts, foreign students are at a higher risk of psychological problems due to stress (Huan, Yeo, Ang, \& Chong, 2006; Lee \& Bradley, 2005; Mortenson, 2006). International students often exhibit a high risk of psychological problems due to numerous necessary adjustments that they have to doin their social, academic and cultural, lives when they become part of a new society. They suffer from loneliness and home sickness because of anxiety, depression and disorientation.

The average level of stress is a normal phenomenon for students, if students study hard in their academic work (Busari, and Uwakwe (2001).

Inventory of academic stress among students at University of Vlora Ismail Qemali who participated in this study, shows that when academic related problems, irritation and other problems encountered at school, the result is incapability, and also the appereance of sad problematic physical and mental health phenomena. (Lin, Y.M and Chen, F.S (2009). Schuler believes that stressis noticed in important opportunities, limitations and needs faced by individuals as well as when the results of these situations are not evident, then individuals create a kind of uncertainty in themselves (Schuler, R.S. 1980).

Teachers often emphasize the acquisition of knowledge and often they neglect the emotional feelings of the students during the teaching process, which can cause emotional stress and problems in learning process to students. In addition, students may feel being in an unfamiliar position as nervousness, anxiety, frustration, humiliation, depression, etc. The instability of these emotions can easily boost strange behavior, which will affect academic achievement and ability to adapt to students if there will be no adequate consultation in time by academic staff and parents, or if they do not get proper attention by friends or family (Chen, F.S, Lin, Y.M and Tu, C.A, 2006).

In their study Agolla, J.E. and Ongori, H, (2009) on academic workload, concluded that (81\%) of the students agreed with the state that the academic workload of academic programs is difficult. This finding is consistent with previous findings (Fairbrother dhe Warn, 2003; Stevenson dhe Harper, 2006; Ongori dhe Agolla, 2008; Agolla, 2009).

Students also fear of failure about their grades and academic performance. Others feel the risk for their academic career prospects or rejection, humiliation, guilt and loss of self-respect (Schafer, 1996). 
Struthers et al. (2000) found that a high level of academic stress was associated with lower grades. Students experience a high level of academic stress because of exams, assignments, time pressure, and uncertainty about the future. In short, stress has a detrimental effect on academic performance.

\subsection{The present study}

The current study seeks to establish an instrument that will provide a reliable measurement and valid answers to students experiencing academic stress and prove how useful is the vision of specific academic problems through answers from college students about experienced stress. Specifically, content, construct, criteria, convergent and divergent validity of the Likert scale will be considered along with reliability.

\section{Methodology}

\subsection{Subject}

In order to achieve the goal of this study, it was used a casual selection of models to conduct thorough and detailed interviews with students. Respondents who willingly answered this pilot study are students of the Faculty of Humanities at the University of Vlora Ismail Qemali. The purpose and objectives of research is seeking was explained to respondents. Respondents were promised anonymity and other ethical norms from other researchers.

\subsection{Respondents' Profile}

From 150 students who were invited to participate in the study, only 130 questionnaires (86.6\%) were taken into consideration by researchers because only them completed the questionnaire. Only those completed questionnaires were used for further statistical and factor analysis. Most of the students were female (70\%) with a frequency distribution and 91 and (30\%) of respondents were males with a frequency distribution 39.

\subsection{Procedures}

In this pilot study, conducted with students of the University of Vlora Ismail Qemali, the instrument used is expected to provide a reliable and valid measurement about the answers of the students about academic experienced stress level during the semester, spring 2013. Statistical Package of Social Sciences (SPSS for Windows XP) was used to perform aresearch analysis of the factors and a formal inventory of this study was created after the analysis done about the reliability and validity of the questionnaire.

\subsection{Instrument}

Instrument used as the primary source the students' responses at the University of Vlora Ismail Qemali. After the analysis and students' opinions a questionnaire of 7 pages was drafted which got divided into three sections and then it was given to students to write about the degree of academic stress that they have experienced during this academic year.

Section One: The demographic data. Students were required to write the gender and university they study. In our study, all participants were students of the University of Vlora.

Section Two: The degree of stress level measurement. Students were asked to report the level of experienced academic stress, considering factors such as; performance of teachers, learning overload, time and self management, academic programs, studying and living conditions, relationships with friends and financial aspects. A five - point scale of Likert type 1 (No stress) to 5 (Extreme stress) was used by researchers to measure the level of stress experienced by students during this academic semester.

Section Three: Scale for measuring the factors's load that influence the increase of stress. A five - point scale, Likert-type was developed by researchers asks the respondents to state their opinions on 69 questions that this section of the questionnaire contains. The purpose of the survey is to meet the first objective of the study, which is the measurement of the degree of reliability with five-point Likert-type, from 1 (Strongly disagree) to 5 (Strongly Agree), conducted and used for purposes of a national valueable study. 


\section{Study Results}

\subsection{Statistical Analysis}

Statistical Package for Social Sciences (SPSS 16.0) was used to analyze the data. The 72 instrument articles were loaded into the (SPSS 16.0) to perform the statistical analysis using descriptive statistics and crossed tables (crosstatbulation), as shown in Table 1 and 2.

Descriptive analysis (dependent variable) of experienced academic stress (Table 1) shows the average (Mean = 3.2). Aaverage error is 0.08869 . Standard Deviation (Std. Deviation) $=1.00344$. So, we can conclude based on the average $($ Mean $)=3.2 \pm 2 * 0.088$ ) that the level of the students experiencing stress includes average and high stress responses on Likert scale, build as a measuring instrument. Expressed in percentage (Table 2), reading the total column, we can see that $37.5 \%$ of students ( $M$ and F) experienced average stress and $38.3 \%$ of students have experienced high stress. So, $75.8 \%$ of the students have experienced average and high stress.

Table 1. Statistics

\begin{tabular}{|c|c|c|}
\hline \multicolumn{3}{|c|}{ Experienced Stress } \\
\hline & Valid & 128 \\
\hline & Missing & 2 \\
\hline & & 3.2188 \\
\hline & & .08869 \\
\hline & & 1.00344 \\
\hline
\end{tabular}

Crosstabulation techniques (crossed tables) in bivariate analysis was conducted by researchers in the descriptive statistical analysis to find relationships between variables (gender) and the dependent variable (experienced stress). From (Table 2), we can notice that $42.7 \%$ of female respondents say that they have experienced average stress. Futhermore, $42.7 \%$ of female respondents, or 38 out of 89 women, say that they have experienced stress on average level, while $25.6 \%$ of male respondents, or 10 out of 39 men say that they have experienced stress on average. Also, we can see that while $43.8 \%$ of female respondents, or 39 out of 89 women have experienced high stress, $25.6 \%$ of male respondents, or 1 out of 39 men have experienced high stress. Also we see that 6 out of 89 women meaning $6.7 \%$ of women have experienced extreme stress, 1 of the 39 men or $2.6 \%$ of the men interviewed have experienced extreme stress. What is noticeable, is first column (count), no stress, where 11 out of 39 men say that they have not experienced stress. So, the percentage of $28.2 \%$ of respondents who say that they have experienced no stress at all, are males. So, from the bivariate analysis crosstabulatin (crossed tables), we conclude that women experienced more stress than men.

Table 2. Experienced Stress * Gender Crosstabulation

\begin{tabular}{|c|c|c|c|c|c|}
\hline & & & \multicolumn{2}{|c|}{ Gender } & \multirow{2}{*}{ Total } \\
\hline & & & 1 & 2 & \\
\hline \multirow{5}{*}{ Experienced Stress } & no stress & $\begin{array}{l}\text { Count } \\
\% \text { within GENDER }\end{array}$ & $\begin{array}{c}11 \\
28.2 \% \\
\end{array}$ & $\begin{array}{c}0 \\
.0 \% \\
\end{array}$ & $\begin{array}{c}11 \\
8.6 \%\end{array}$ \\
\hline & few stress & $\begin{array}{l}\text { Count } \\
\% \text { within GENDER }\end{array}$ & $\begin{array}{c}7 \\
17.9 \% \\
\end{array}$ & $\begin{array}{c}6 \\
6.7 \% \\
\end{array}$ & $\begin{array}{c}13 \\
10.2 \% \\
\end{array}$ \\
\hline & Average stress & $\begin{array}{l}\text { Count } \\
\% \text { within GENDER }\end{array}$ & $\begin{array}{c}10 \\
25.6 \%\end{array}$ & $\begin{array}{c}38 \\
42.7 \% \\
\end{array}$ & $\begin{array}{c}48 \\
37.5 \% \\
\end{array}$ \\
\hline & A lot of stress & $\begin{array}{l}\text { Count } \\
\% \text { within GENDER }\end{array}$ & $\begin{array}{c}10 \\
25.6 \% \\
\end{array}$ & $\begin{array}{c}39 \\
43.8 \% \\
\end{array}$ & $\begin{array}{c}49 \\
38.3 \% \\
\end{array}$ \\
\hline & Extreme stress & $\begin{array}{l}\text { Count } \\
\% \text { within GENDER }\end{array}$ & $\begin{array}{c}1 \\
2.6 \%\end{array}$ & $\begin{array}{c}6 \\
6.7 \%\end{array}$ & $\begin{array}{c}7 \\
5.5 \%\end{array}$ \\
\hline \multicolumn{2}{|c|}{ Total } & $\begin{array}{l}\text { Count } \\
\% \text { within GENDER }\end{array}$ & $\begin{array}{c}39 \\
100.0 \%\end{array}$ & $\begin{array}{c}89 \\
100.0 \%\end{array}$ & $\begin{array}{c}128 \\
100.0 \% \\
\end{array}$ \\
\hline
\end{tabular}




\subsection{Analysis of reliability}

To ensure the reliability and validity of the instrument, as evidence of the reliability of Likert scale, measurement of Cronbach's Alpha for the 69 variables was conducted. In order to ensure validity, the instrument was conducted with students of the Faculty of Humanities at the University of Vlora. Their views and comments about the factors presented in the questionnaire met the goals and objectives of this study. As seen from (Table 3), analysis of the reliability of Likert scale that was used in this study as a tool to evaluate the reliability of the variables that have an impact in the increase of the students' academic stress, gives us an excellent coefficient.

So, overall rate coefficient of Cronbach's Alpha $=0.956$ (Excellent).

Table 3. Reliability Statistics

\begin{tabular}{|c|c|}
\hline Cronbach's Alpha & N of Items \\
\hline .956 & 69 \\
\hline
\end{tabular}

Reliability analysis of the factor: Stress from results (Table 4). The scale coefficient of Cronbach's Alpha $=0.868$ (Acceptable).

Table 4. Reliability Statistics

\begin{tabular}{|c|c|c|}
\hline Cronbach's Alpha & Cronbach's Alpha Based on Standardized Items & N of Items \\
\hline .868 & .873 & 16 \\
\hline
\end{tabular}

Reliability analysis of the factor: Self-managment (Table 5). The scale coefficient of Cronbach's Alpha $=0.734$ (Acceptable)

Table 5. Reliability Statistics

\begin{tabular}{|c|c|c|}
\hline Cronbach's Alpha & Cronbach's Alpha Based on Standardized Items & N of Items \\
\hline .734 & .742 & 9 \\
\hline
\end{tabular}

Reliability analysis of the factor: Stress from programmes (Table 6). The scale coefficient of Cronbach's Alpha $=0.795$ (Acceptable).

Table 6. Reliability Statistics

\begin{tabular}{|c|c|c|}
\hline Cronbach's Alpha & Cronbach's Alpha Based on Standardized Items & N of Items \\
\hline .795 & .797 & 4 \\
\hline
\end{tabular}

\subsection{Analysis of the product - moment correlation.}

To view the link between experiencing stress and stress factors from the results, it was used the correlation coefficient of Pearson's product - moment. The data show (Table 7) that there is a positive linear relation between stress levels and student outcomes. This means that there is a valid statistical relationship (substantial) between variables (dependent variable - experienced stress) and (independent variable - stress factor from results). This means that changes in stress variable results are strongly related to changes in the dependent variable, experiencing stress. In (Table 7) it is clearly noticed that $r$ Pearson is 0.6 . For this reason, we can conclude that it is a statistically significant relationship (correlation is substantial).

However, we can not come to any other conclusion about this relationship, based on this coefficient. Value Sig. (2- 
tailed) shows that there is a statistically significant correlation between variables. In our example, Sig (2-tailed), the value is $0,000 p<0: 05$. So, the correlation is significant at a confident level of $95 \%$ (or 0.05 level). As long as the value is under, 050 , correlation is significant at $95 \%$ level. The theory of probability states that the lower the number of Sig (2tailed), the more significant is the relationship between variables. $95 \%$ secured, it means that probably $95 \%$ of respondents state that there is a correlation between two variables that do not depend on casual factors. We can conclude that there is a statistically significant correlation between the two analyzed variables This means, increases or decreases in one variable (independent stress variable from results) will contribute significantly to increase or decrease the level of stress experienced by students (dependent variable).

Table 7. Correlations

\begin{tabular}{|ll|c|c|}
\hline & Pearson Correlation & 1 & $.600^{* *}$ \\
F.2 Stress From Results & Sig. (2-tailed) & & .000 \\
& $\mathrm{~N}$ & 123 & 121 \\
\hline \multirow{3}{*}{ Experienced Stress } & Pearson Correlation & $.600^{\text {** }}$ & 1 \\
& Sig. (2-tailed) & .000 & \\
& $\mathrm{~N}$ & 121 & 128 \\
\hline
\end{tabular}

**. Correlation is significant at the 0.01 level (2-tailed).

Viewing the analyzed data (Table 8), we conclude that there is a linear positive correlation between the stress level experienced by the students and self-management factor. This means that there is a valid statistical relationship (substantial) between variables (dependent variable - experienced stress) and (independent variable - stress factor from results). So, we can conclude that changes in the stress variable from self-management are associated with changes in the dependent variable, experiencing stress. In (Table 8), it is clearly noticed that $r$ Pearson is 0.6. Value Sig. (2-tailed) shows that there is a statistically significant correlation between variables. In our example, Sig (2-tailed), the value is 0,000 . $p<0: 05$. So, the correlation is significant at a confident level of $95 \%$ (or 0.05 level). For this reason, we can conclude that the relationship between two variables is a statistically significant relationship (correlation is substantial).

Table 8. Correlations

\begin{tabular}{|ll|c|c|}
\hline & Pearson Correlation & 1 & $.605^{* *}$ \\
Experienced Stress & Sig. (2-tailed) & & .000 \\
& $\mathrm{~N}$ & 128 & 123 \\
\hline \multirow{3}{*}{ F.5 Stress from Self-Managment } & Pearson Correlation & $.605^{* *}$ & 1 \\
& Sig. (2-tailed) & .000 & \\
& $\mathrm{~N}$ & 123 & 125 \\
\hline
\end{tabular}

**. Correlation is significant at the 0.01 level (2-tailed).

By analyzing and interpreting the results (Table 9), we notice that there is a positive linear relation between stress levels and student outcomes. This means that there is a valid statistical relationship (substantial) between variables (dependent variable - experienced stress) and (independent variable - program stress factor). This means that changes in stress variable from programs are related to changes in the dependent variable, experienced stress. In (Table 9) it is clearly seen that $r$ Pearson is 0.6 . Value Sig. $(2$ - tailed) shows that there is a significant correlation statistically between variables. In our example, Sig (2-tailed), the value is 0,000. $p<0: 05$. For this reason, we can conclude that the relationship between two variables is a statistically significant relationship (correlation is substantial). 
Table 9. Correlations

\begin{tabular}{|ll|c|c|}
\hline & & Experienced Stress & F.7 Stress from Programmes \\
\hline \multirow{3}{*}{ Experienced Stress } & Pearson Correlation & 1 & $.551^{* *}$ \\
& Sig. (2-tailed) & & .000 \\
& $\mathrm{~N}$ & 128 & 126 \\
\hline \multirow{3}{*}{ F.7 Stress From Programmes } & Pearson Correlation & $.551^{* *}$ & 1 \\
& Sig. (2-tailed) & .000 & 128 \\
\hline
\end{tabular}

**. Correlation is significant at the 0.01 level (2-tailed).

To test the null hypothesis, it was used Anova test by researchers. As it is seen (Table 10) Sig $=0.000$. The fact that the probability of error is $p<0.0,5$ it is needed to reject the null hypothesis and conclude that the self-management factors, the results of research and stress from academic programs affect in the increase of students' academic stress level.

Table 10. ANOVA

\section{Experienced Stress}

\begin{tabular}{|c|c|c|c|c|c|}
\hline & Sum of Squares & $\mathrm{df}$ & Mean Square & $\mathrm{F}$ & Sig. \\
\hline Between Groups & 57.660 & 15 & 3.844 & 6.079 & .000 \\
Within Groups & 69.554 & 110 & .632 & & \\
Total & 127.214 & 125 & & & \\
\hline
\end{tabular}

\section{Discussion}

Starting from the reached results of the statistical analysis, we conclude that students have experienced academic stress. The fact that $37.5 \%$ of students ( $\mathrm{M}$ and $\mathrm{F}$ ) experienced average stress and $38.3 \%$ of students have experienced high stress, is evidence to claim that the hypothesis $\mathrm{H}_{0}$ drops and the alternative hypothesis $\mathrm{H}_{1}$ meets the final target of this study. So, in total $75.8 \%$ of students have experienced average and high stress is a significant result to confirm the alternative hypothesis. Also, from the analysis of data results we conclude that women experienced higher levels of academic stress than men.

Taking into consideration the results of the bivariate correlation analysis between analyzed factors analyzed in this study, between factors namely: self-management, research results and academic programs and variable experiencing stress, we conclude that these factors have led to the increase of students'stress levels. Definitely, there are other factors that were not analyzed in this study. Thus, the results support the alternative hypothesis of the study that a positive linear correlation will be found between the examined variables and academic stress level experienced by the students.

\section{Conclusions and Recommendations}

Results of the study provide important insights for a better self-management and reducing anxiety about certain leisure activities to reduce academic stress. The findings in this study are also consistent with previous researches on academic stress and show that placing situations under control, is related to lower levels of stress. Furthermore, using an organizational approach to manage themselves students can reduce the impact of academic stress factors. In accordance with various tests of reliability and validity mentioned above, earlier examining inventory of academic stress of this study showed satisfactory results. It is important for universities to maintain a balanced academic environment conducive to better learning, focusing on meeting the personal needs of students. University students hope to fulfill their goals and personal values, which are possible only if the student expectations, goals and values are integrated with the university (Goodman, 1993).

Our study also found that the main causes of stress among students are academic workload, academic programs, academic poor performance, low motivation, lack of experience in managing themselves and the situations faced by the students.

Based on the findings and discussions above, we would like to bring forward some suggestions and 
recommendations to relevant authorities. First of all, we propose to maintain the lecturer - student ratiolrelation. This is also because the results show that this is one of the possible reasons to reduce the stress levels of the students.

We would also suggest about management staff in universities, to constantly plan appropriate activities and programs for students such as; organizing talks on motivation, self-management, and time and increasing study skills. Such programs and activities will help students to reduce stress levels or at least increase their knowledge to control their stress because this will directly contribute to their academic achievements.

In addition, the planning of sports and recreational activities should be improved to provide more opportunities for students to engage in such activities. Of course, involvement in these activities is one of the possible ways to help students to reduce their stress. Of course, this study had limitations because of the small research.

\section{References}

Agolla, J.E. "Occupational Stress among Police Officers." The case of Botswana Police service, Res. J. Bus. Manage. 2 (1), 2009: 25-35. Agolla, J.E. and Ongori, H. "An assessment of academic stress among undergraduate students: The case University of Botswana. ." Educational Research and Review, Vol. 4(2), 2009: 063-070.

Busari,A.O.\&Uwakwe,C.B.U. "The Effect of stress inoculation Trajning Technique In The Managment Of Worry As A Self- handicapping Strategy In intellectual Performance." Nigerian Journal Of Emotional Psychology And Sport Ethics, 3, 2001: 6-12.

Basch, C.E. and Kersch, T.B. "Adolescent perceptions of stressful life events." Health Education, June/July1986: 4-7.

Brown, R.P., \& Lee, M.N. "Stigma consciousness and the race gap in college academic achievement. Self and Identity,4." 2005: 149157.

Chen, F.S., Lin, Y.M. and Tu, C.A. "A study of the emotional intelligence and life adjustment of senior high school students." World Transactions on Engng. and Technol. Educ., 5, 3, 2006: 473-476.

Fairbrother K, Warn J. "Workplace Dimensions, Stress and Job Satisfaction,." J. Managerial Psychol. 18(1):, 2003: 8-21 Goodman E, D. "How to handle the stress of being a student." Imprint, 1993: 40-43.

Goodman E, D. "How to handle the stress of being a student." Imprint, 1993: 40-43.

Groer, M.W., Thomas, S.P. and Shoffer, D., 209-217 (1992). . "Adolescent stress and coping: a longitudinal study. ." Research in Nursing \& Health, 15, 1992: 209-217.

Huan, V.S., Yeo, L.S., Ang, R.P., \& Chong, W.H. "The influence of dispositional optimism and gender on adolescents' perception of academic stress." Adolescence, 41, 2006: 533-546.

Lin, Y.M. and Chen, F.S. "Academic stress inventory of students at universities and colleges of technology,." World Transactions on Engineering and Technology Education, Vol.7, No.2, 2009.

Mates, D. and Allison, K.R. "Sources of stress and coping responses of high students." J. of Adolescence, 27, 1992: 461-474.

Mortenson, S.T. "Cultural differences and similarities in seeking social support as a response to academic failure: A comparison of American and Chinese college students." 2006: 127-146.

Ongori H, Agolla JE. "'"Occupational Stress in Organisations and Its Effects on Organisational Performance, ." J. Manage. Res. 8(3), 2008: 123-135.

Plunkett, S.W., Radmacher, K.A. and Moll-Phanara, D.,. "Adolescent life events, stress, and coping: a comparison of communities and genders." Professional School Counseling, 3, 5, 2000: 356-366.

Stren, M. and Zevon, M. "stress,coping, and family environment: the adolescent's response to naturally occurring stressors." J.of adolescent Research, 5, 1990: 290-305.

Schuler, R.S. "Definition and conceptualization of stress in organizations,." Organizational Behavior and Human Performance, 25, 2,, 1980: 184-215.

Stevenson A, Harper S. "Workplace stress and the student learning experience." Qual. Assur. Educ., 14(2), 2006: 167-178.

Schafer, W. " Stress management for wellness. Passing the test of college stress." In W. Schafer (Ed.),, 1996: 543-546. 